\title{
A prática do design de informação para conhecimento no território: memórias de um experimento urbano em Fortaleza
}

\author{
The practice of information design for knowledge in territory: memories of an urban \\ experiment in Fortaleza
}

Ariane de Almeida Mendes

experimento, comum, Praia de Iracema, informação, criatividade

Fortaleza foi recentemente inserida na rede de cidades criativas da UNESCO no campo do Design, evidenciando os setores da economia criativa enquanto estratégicos em seu desenvolvimento sustentável urbano. O projeto PI EXPERIMENTAL é proposto como espaço investigativo do bairro Praia de Iracema, distrito criativo da capital cearense, a fim de testar e comunicar boas práticas de inovação no território a partir de ferramentas combinadas de gestão e design. Em encontros híbridos para reflexão e coprodução, o laboratório foi se re-desenhando coletivamente nas vivências, dinâmicas e memórias comuns das mulheres-pesquisadoras, levantando temas como tecnologia social, disputa de narrativas e o potencial comunitário na transformação urbana.

experiment, commons, Praia de Iracema, information, creativity

Fortaleza was recently inserted in UNESCO's network of creative cities in the field of Design, showing the creative economy as strategic in their sustainable urban development. PI EXPERIMENTAL project is proposed as an investigative space at Praia de Iracema neighborhood, creative district in capital of Ceará, to test and communicate best practices of territory innovation using combined management and design tools. In hybrid meetings for reflection and co-production, the laboratory was redesigning itself collectively in the experiences, dynamics and common memories of women-researchers, raising issues such as social technology, dispute of narratives and the community potential in urban transformation.

\section{Introdução}

No final do ano de 2019, Fortaleza foi inserida na rede de cidades criativas da UNESCO. A chancela no campo do Design pressupõe o comprometimento com o desenvolvimento de parcerias e o compartilhamento de melhores práticas criativas, prezando pelo acesso e participação na vida cultural. O bairro Praia de Iracema, que com o passar do tempo tem vivenciado diversas transformações de usos e identidades, atualmente é promovido como distrito criativo fortalezense, sendo reconhecido como lugar de encontro, boêmia, cultura e intelectualidade na cidade.

O projeto PI EXPERIMENTAL surge através do edital "CRIA PI" articulado pelo Instituto Cultural Iracema, organização social atuante no bairro em questão e vinculado à Prefeitura

Anais do $10^{\circ} \mathrm{CIDI}$ e $10^{\circ} \mathrm{CONGIC}$

Kelli C.A.S. Smythe, Rafael de Castro Andrade (orgs.)

Sociedade Brasileira de Design da Informação - SBDI

Curitiba | Brasil | 2021
Proceedings of the $10^{\text {th }} \mathrm{CIDI}$ and $10^{\text {th }}$ CONGIC

Kelli C.A.S. Smythe, Rafael de Castro Andrade (orgs.)

Sociedade Brasileira de Design da Informação - SBDI Curitiba | Brazil | 2021 
Municipal de Fortaleza. A jornada investigativa na Praia de Iracema foi projetada, apresentada e gerida pela autora deste documento, compondo o total de 20 projetos selecionados no programa de fomento para ideias criativas no território. A proposta parte da intenção de desenvolver um espaço propício à experimentação e à divulgação de boas práticas inovadoras no contexto urbano.

A partir dos eixos "Praia de Iracema", "Comum" e "Experimento" o projeto atuou no desmembramento da ideia do design enquanto produção de artefato ou produto final materializado na cidade. Através do desenho de informação e de seus fluxos durante todo o processo de execução, o PI EXPERIMENTAL provoca a prática do design para a construção coletiva, buscando evidenciá-la enquanto ferramenta para organização, entendimento e produção de conhecimento na cidade.

\section{Contextualização}

O bairro Praia de Iracema - que também foi e segue sendo "Praia dos Peixes", "Lido", "Praia dos Amores", "Praia dos Crush" - tem sido o palco para movimentos criativos em Fortaleza. Mistura de lugar tradicional com ponto turístico, natureza urbana e diversidade de encontros, é tanto espaço de memória quanto também o é de abandono. É território de privilégio na cidade e atravessa ao longo dos anos embates entre o que foi e o que está, como se o tempo agisse diferente entre as fronteiras do bairro, que não necessariamente cumprem o estabelecido pela delimitação de órgãos oficiais: quase como ideia (ou poesia), a Praia de Iracema vai até onde cada um a sente.

Nos último anos na cidade de Fortaleza, o design foi propagado como elemento metodológico no desenvolvimento urbano sustentável, sendo inserido na pauta da governança, em projetos educacionais, além de ser nacionalmente reconhecido na agenda da mobilidade urbana a partir da implementação de ciclovias, corredores de ônibus, integração de modais, dentre outros redesenhos que apontam para o projeto criativo urbano.

\section{Problema}

Ainda que o discurso do design tenha sido introduzido na recente gestão municipal em Fortaleza, existem barreiras de experimentação na escala da cidade, especialmente quando os testes acontecem por meio da organização comunitária e buscam repensar o modelo como se pensa o espaço comum. A criatividade precisa ultrapassar as restrições de escassez: diante das dificuldades e problemas socialmente herdados, onde mora a criação por envolvimento e enquanto poder coletivo? O projeto PI EXPERIMENTAL parte, então, na busca de perguntas ao invés de respostas prontas. Onde está a Praia de Iracema? O que é o comum? Como fazer um experimento?

Considerando o caráter essencial da atividade de pesquisa no contexto brasileiro e resgatando a potencialidade educacional do estado do Ceará, a jornada investiga os pontos comuns entre os territórios individuais e comunitários a partir da prática do design, usando-o como ferramenta para participação, pertencimento e cidadania. A partir disso, a pesquisa 
experimental também encara o impasse entre conceitos exportados de desenvolvimento e a necessidade de pensar o local pelo olhar de quem o habita. Por fim, com o desenho selecionado via edital no início de 2020 , o projeto é fruto de adaptações às novas formas de interagir, ocupar e colaborar com a cidade nas limitações sanitárias decorrentes do Covid-19.

\section{Objetivos}

1. Evidenciar o uso do Design de Informação no projeto PI EXPERIMENTAL e em suas operações no território;

2. Documentar testes e práticas promovidas na iniciativa PI EXPERIMENTAL para que sirvam de inspiração a outras iniciativas sociais em comum;

3. Demonstrar a relevância das ferramentas do design na organização de grupos de trabalho e na produção de conhecimento;

4. Promover a pesquisa e o experimento no território, facilitando modos de fazer através de desenhos possíveis para articulação urbana.

\section{Referencial Teórico}

O conceito de cidade sustentável se apresenta em muitas facetas: é também uma cidade justa, bonita, criativa, ecológica, fácil, compacta e policêntrica, diversificada. Ao considerar a sustentabilidade social, Gehl (2015) aponta que a cidade deve cumprir a função democrática de ser lugar de compartilhamento entre pessoas de diversos contextos sociais, convidando ao encontro e a uma maior compreensão do outro. Almejando o desenvolvimento urbano a partir da inovação, de acordo com Rogers (2011), uma cidade criativa é onde uma visão aberta e a experimentação mobilizam todo o seu potencial de recursos humanos e permitem uma rápida resposta à mudança.

A criatividade em geral, por sua vez, se baseia em processos controláveis, como atenção, observações e análise, bem como, em certa medida, pela flexibilidade e eficiência no trabalho intelectual que são permitidos a partir do conhecimento de seus métodos (Frascara, 2000). uso do desenho pela hipotetigrafia, ou seja, do produto gráfico que auxilia na visibilidade de hipóteses, nasce de um processo intuitivo a partir de capacidades criativas, tornando difícil pressupor os resultados a serem atingidos a partir do modelo de simulação delineado inicialmente (Massironi, 1937). É na direção convergente entre inteligência e criatividade, processos administráveis e espontâneos, em busca da natureza aberta e comum da ciência, que se encontra o formato de laboratórios cidadãos.

Segundo Lafuente (2015, p. 1), “um laboratório cidadão é um lugar de produção de novas formas de visualizar, mapear e representar os problemas; (...) é um lugar onde se estão experimentando novas formas de cidadania e novas formas de conhecer". A tarefa de ensinoaprendizagem reside no lugar onde há possibilidades para a disseminação do conhecimento a partir da sua própria produção, destacando a sabedoria inerente à materialidade do espaço físico (Freire, 2004). Dentre os processos de autorreforço que permitem o florescimento de pequenos eventos, surpresas que dão vida ao urbano, destaca-se a combinação de bons 
hábitos e rotinas, um bom espaço público e massa crítica em torno da cidade (Gehl, 2015). Se os bairros puderem ser entendidos como laboratórios de experimentos comunitários, as ruas então serão territórios de acontecimento, e desses acontecimentos outros surgirão.

"A experiência, a possibilidade de que algo nos aconteça ou nos toque, requer um gesto de interrupção, um gesto que é quase impossível nos tempos que correm: requer parar para pensar, parar para olhar, parar para escutar, pensar mais devagar, olhar mais devagar, e escutar mais devagar; parar para sentir, sentir mais devagar, demorar-se nos detalhes, suspender a opinião, suspender o juízo, suspender a vontade, suspender o automatismo da ação, cultivar a atenção e a delicadeza, abrir os olhos e os ouvidos, falar sobre o que nos acontece, aprender a lentidão, escutar aos outros, cultivar a arte do encontro, calar muito, ter paciência e dar-se tempo e espaço." (Bondía, 2002)

Um processo geral para o mapeamento de experiências é composto por quatro modos iterativos de atividade: iniciar, investigar, ilustrar e alinhar (Kalbach, 2017). A cartografia das tentativas, das vivências no lugar-comum, é portanto composta por dados, elementos informacionais derivados da prática de pesquisa. De modo simplificado Wurman (1991) elenca cinco divisões pelas quais as informações cercam a vida cotidiana: interna (referente ao corpo e sistemas internos humanos), conversacional (a partir de trocas formais e informais entre pares), de referência (pela ciência e tecnologia), noticiosa (acontecimentos via mídias diversas) e cultural (incluindo história, filosofia, artes e outras expressões que auxiliam na compreensão da civilização). Na sociedade pós-industrial, acometida pela aceleração e digitalização, a informação vem recebendo destaque e valor social, político e cultural. Nesse contexto Han (2019) alerta para a pobreza narrativa do processo: sem toques misteriosos, coreografias ou teatralidades que acompanham o relato, o processo não passa de objeto administrativo funcional.

Ao centrar o olhar para o bairro Praia de Iracema, o experimento urbano busca também construir uma narrativa além-fronteiras do distrito criativo cearense, uma vez que:

"As imagens e representações acerca deste bairro parecem sintetizar um conjunto de elementos que diz respeito à cidade, a saber, a preservação do património material e simbólico de Fortaleza, no sentido da sua memória e manutenção de equipamentos públicos. A Praia de Iracema pode ser definida como sinalizadora do êxito ou fracasso das políticas municipais, e mesmo estaduais." (BEZERRA, 2008, p.212)

Diante da complexidade envolvendo o debate proposto no laboratório PI EXPERIMENTAL, entre ramificações de uso do desenho, conceitos urbanísticos, ferramentas e processos de gestão, construção e pertencimento da equipe investigadora junto ao território, o design de informação incorpora o papel integrador entre disciplinas. Através da inserção de técnicas e princípios simples do design de informação no processo de desenvolvimento (tais como identificar e traçar objetivos, relembrar e hierarquizar informações valiosas, construir sentido e visualizar estruturas complexas a partir elementos gráficos), é possível obter benefícios e solucionar desafios de comunicação (Knemeyer, 2003). 


\section{Metodologia}

A metodologia se inspira na tríplice imersão-cocriação-prototipação do Design Thinking e desenha circuitos entre as fases a fim de quebrar a linearidade do desenvolvimento.

As etapas (Tabela 1) foram desenhadas de modo a permitir a adaptação e a apreensão de novos acontecimentos, reconhecendo metodologicamente que "seria no espaço, não no espaço predeterminado, mas nos "entres", nos espaços livres de preconfigurações, que vivenciaríamos esses "momentos de invenção" e criaríamos condição para o devenir autre "1" (Guatelli, 2012, p. 32).

Tabela 1: Etapas da Jornada PI EXPERIMENTAL

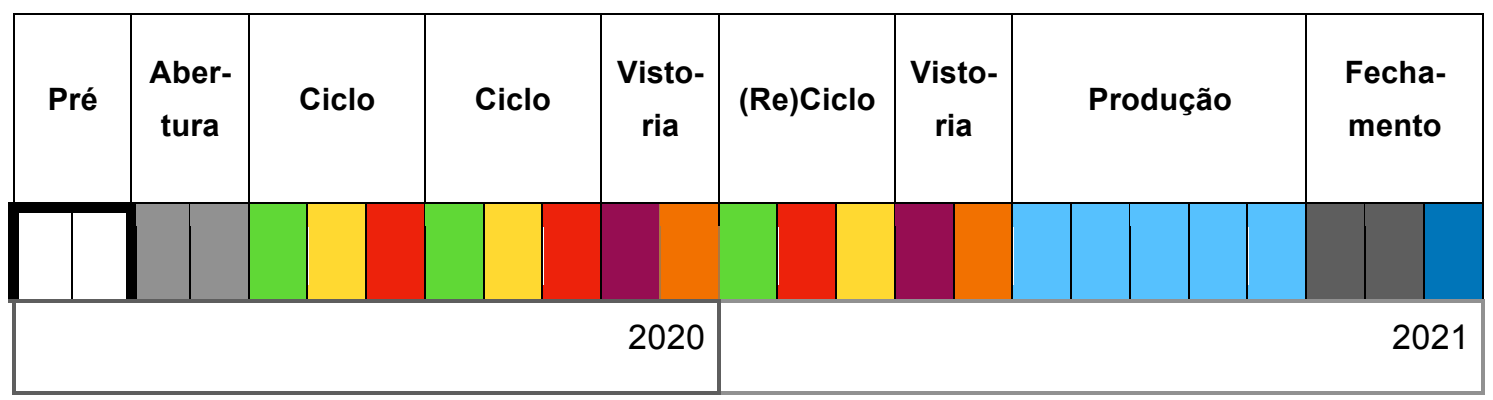

No total de 25 (vinte e cinco) encontros distribuídos entre 4 (quatro) meses de desenvolvimento, o projeto objetivou adentrar a Praia de Iracema a partir da pesquisa experimental que culminaria na produção de um objeto comunicador do bairro. Nas fases de "Pré" e "Abertura", buscou-se eleger membros para a equipe investigadora através de formulários em linguagem simples divulgados em equipamento parceiro no bairro e via redes sociais. Os critérios de seleção considerados foram: relação com o território, disponibilidade de tempo e motivação para as atividades, multidisciplinaridade do time. Como na carta de Nurit Bensusan (2019, p. 134) à Ailton Krenak, a chamada aberta se confiou na ideia de que "é de onde você veio até onde eu vim e de onde eu vim até onde você veio que acontece o encontro".

Os ciclos de imersão compostos por encontros de "MENTORIA", "VISITA TÉCNICASENSITIVA" e "OBSERVAÇÕES" servem para aumentar a familiaridade com o território e com a inovação urbana, dispondo de revisões bibliográficas, pesquisa de campo e ação participativa. Os encontros denominados "APRENDIZADOS" e "PROTOTIPAGEM" compõem a vistoria, ou seja, o momento onde a equipe analisa os procedimentos já concebidos e propõem modelos possíveis para o objeto comunicador final, que viria a ser co-produzido em seguida. Após a finalização do produto final, são delineados encontros para a apresentação do mesmo, para organizar a documentação referente ao projeto e, não menos importante, para a celebração junto à equipe, marcando o valor de atividades pós-produção e de interações afetivas e comemorativas para a memória do processo. Cada encontro abarca 2,5 horas de

\footnotetext{
${ }^{1}$ A expressão devenir autre vem da língua francesa e em tradução direta significa "tornar-se outro". Usada nesse contexto enquanto acontecimento, florescimento de eventos além do previamente programado.
} 
trabalho colaborativo, prezando pela pontualidade. A descrição das etapas em tipos de encontro apresenta-se na Tabela 2.

Tabela 2: Encontros por etapa no PI EXPERIMENTAL

\begin{tabular}{llc}
\hline & \multicolumn{1}{c}{ ETAPO DE ENCONTRO } & QUANTIDADE DE DIAS \\
\hline Pré & ALINHAMENTO INTERNO & 2 \\
\hline Abertura & CHAMADA ABERTA & 2 \\
\hline \multirow{2}{*}{ Ciclo } & MENTORIA & 3 \\
\cline { 2 - 3 } & VISITA TÉCNICA-SENSITIVA & 3 \\
\hline \multirow{2}{*}{ Vistoria } & OBSERVAÇÕES & 3 \\
\hline Produção & APRENDIZADOS & 2 \\
\hline & PROTOTIPAGEM & 2 \\
\hline Fechamento & ACOMPANHAMENTO & 1 \\
\hline JORNADA & EXIBIÇÃO & 1 \\
\hline & RELATORIA & 1 \\
\hline & CELEBRAÇÃO & TOTAL de \\
\hline
\end{tabular}

\section{Técnicas}

Objetivando captar informações comuns à equipe e ao território, durante a jornada foram estimuladas técnicas pertencentes aos campos do design, do urbanismo e da gestão. Além de disseminar procedimentos de interação entre grupos e lugares, os encontros serviram como momentos de ensino-aprendizagem, facilitando discussões que, por vezes, se isolam em ambientes acadêmicos e trazendo para a vivência da rua seus desdobramentos e considerações práticas.

\section{Mapeamento}

A partir da formação da equipe investigadora (composta por seis mulheres pesquisadoras), percebeu-se a necessidade de trazer a perspectiva feminina para a Praia de Iracema, uma vez que o bairro historicamente apresenta casos de insegurança e vulnerabilidade às mulheres. Para abordar e problematizar o território em suas características sociais, subjetivas e geográficas, foram utilizados recursos de mapeamento e cartografias, de modo a também 
fornecer estratégias para a criação de novos discursos, evidenciando olhares para além do hegemônico patriarcal.

"A construção de novas histórias e narrativas territoriais requerem ferramentas que promovam a participação e que estimulem a reflexão a partir de olhares dialógicos. Nesse sentido, o desenho e a ativação de um arsenal de recursos visuais (iconografias, pictogramas, dispositivos gráficos e cartográficos) estabelecem uma plataforma de trabalho que estimula a lembrança, troca e sinalização dos temas." (Risler \& Ares, 2013, p. 14)

Para integrar e adaptar as pesquisadoras nas atividades da jornada, foram utilizados Mapas Conceituais: a atividade colaborativa consistia em descrever as palavras-pilares do projeto "Praia de Iracema", "Comum", "Experimento". A tarefa de definição (Figura 1) partiu de questionamentos sobre o que é, onde se encontra e como se manifesta o design no cotidiano e em atividades profissionais, promovendo o reconhecimento de hábitos em estudos e pesquisas que se aproximam da disciplina em questão. A técnica serviu para elaborar um vocabulário comum entre as integrantes, a fim de compartilhar o entendimento das bases da investigação ao longo do seu desenvolvimento.

Figura 1: Mapas conceituais “Design?”, "Comum", "Experimento"e "Praia de Iracema”. Fonte: Arquivo do projeto.

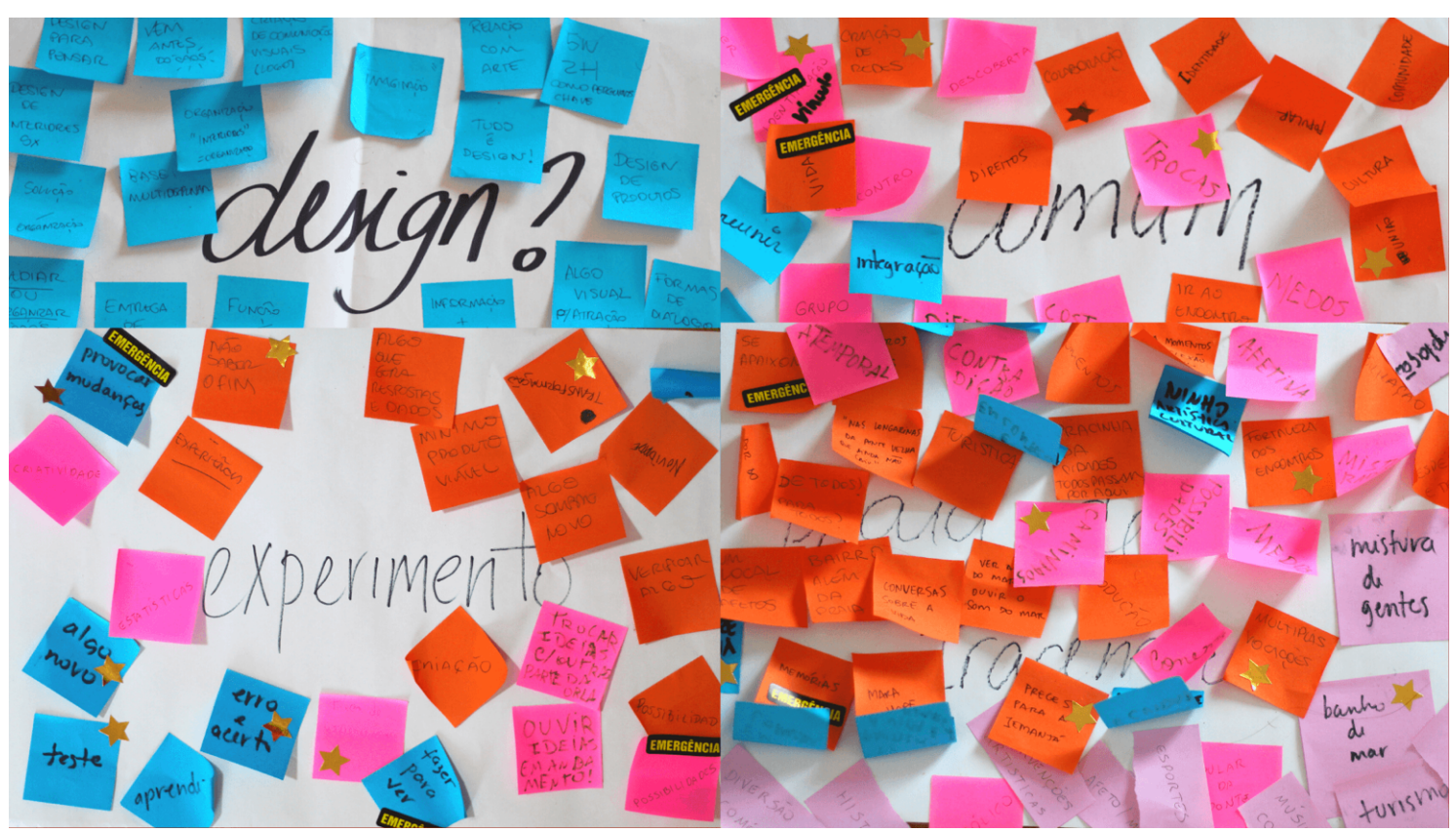

Outra técnica empregada se relaciona com a cartografia do território. Por se tratar de uma zona de interesse turístico, a orla da Praia de Iracema é destacada em produções sobre o lugar. O exercício de mapa mental foi motivado pelo resgate da memória e da identificação das participantes com o espaço físico: em uma cartolina branca, buscou-se desenhar ruas, equipamentos, pontos de interesse e outros elementos que representam o bairro numa cartografia própria, personalizável, marcada pelas lembranças e construções mentais do grupo 
(Figura 2). O mapa serviu como visualização de zonas esquecidas, pouco lembradas ou desconhecidas, sendo suporte para posteriores atividades focais.

Figura 2: Exercício de Mapa Mental da Praia de Iracema. Fonte: Arquivos do projeto.

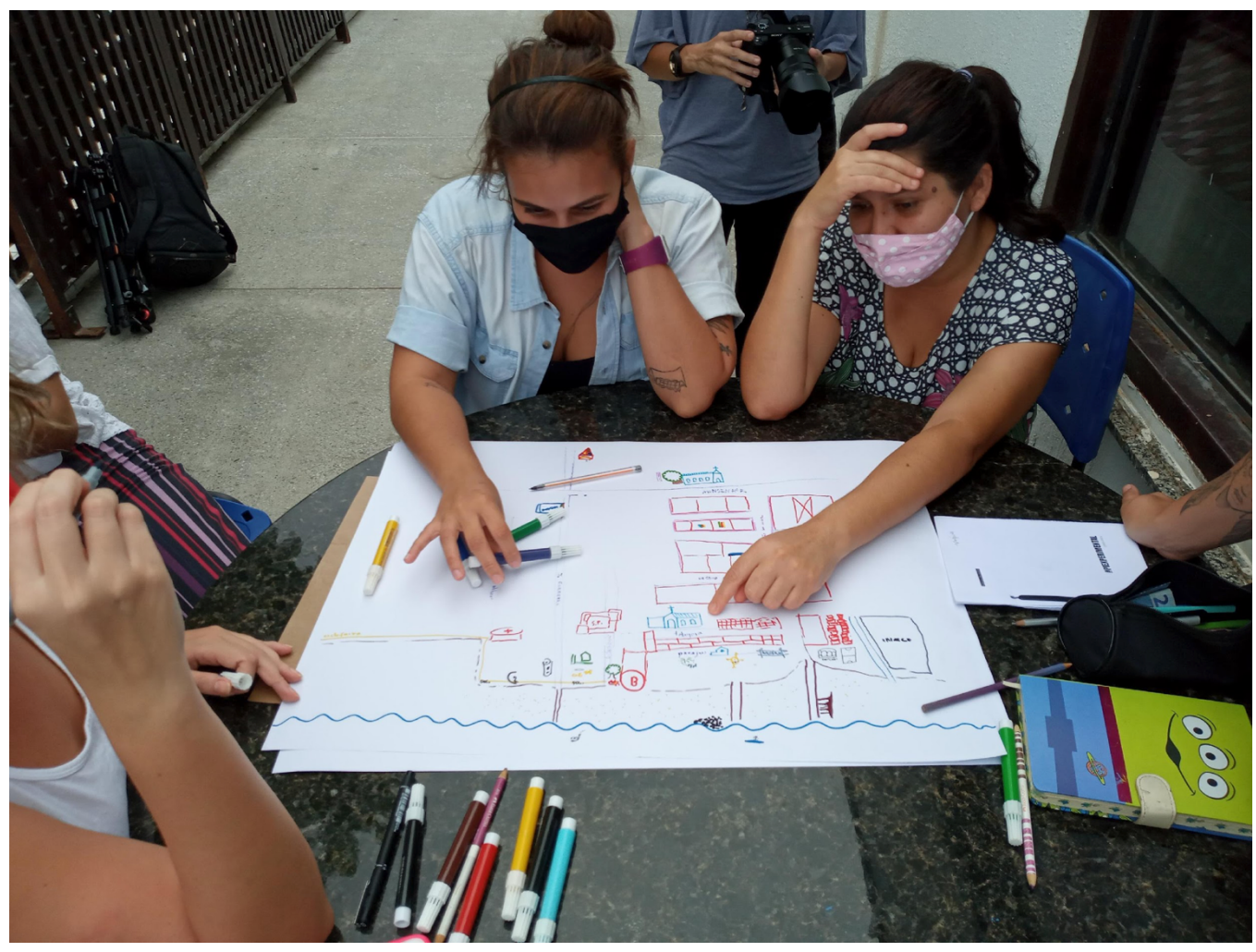

O uso de cartografias também foi aplicado para reconhecimento do bairro, elencar pontos de concentração e atração, sendo referência de representação do espaço geográfico (Figura 3). Foram reunidos mapas da Praia de Iracema produzido por outros grupos e instituições, reparando em temáticas e categorizações abordadas nestes. A ideia de provocar a imagem do território enriqueceu os encontros, trazendo as integrantes a refletir sobre a própria presença naquele espaço específico. Ainda que não fizessem parte do produto final a ser apresentado, a ação de mapear auxilia no suporte gráfico e visual para a organização da complexidade em trabalhos coletivos. 
Figura 3: Dinâmica para agrupamento de pontos de interesses no bairro utilizando mapa impresso. Fonte: Arquivos do projeto

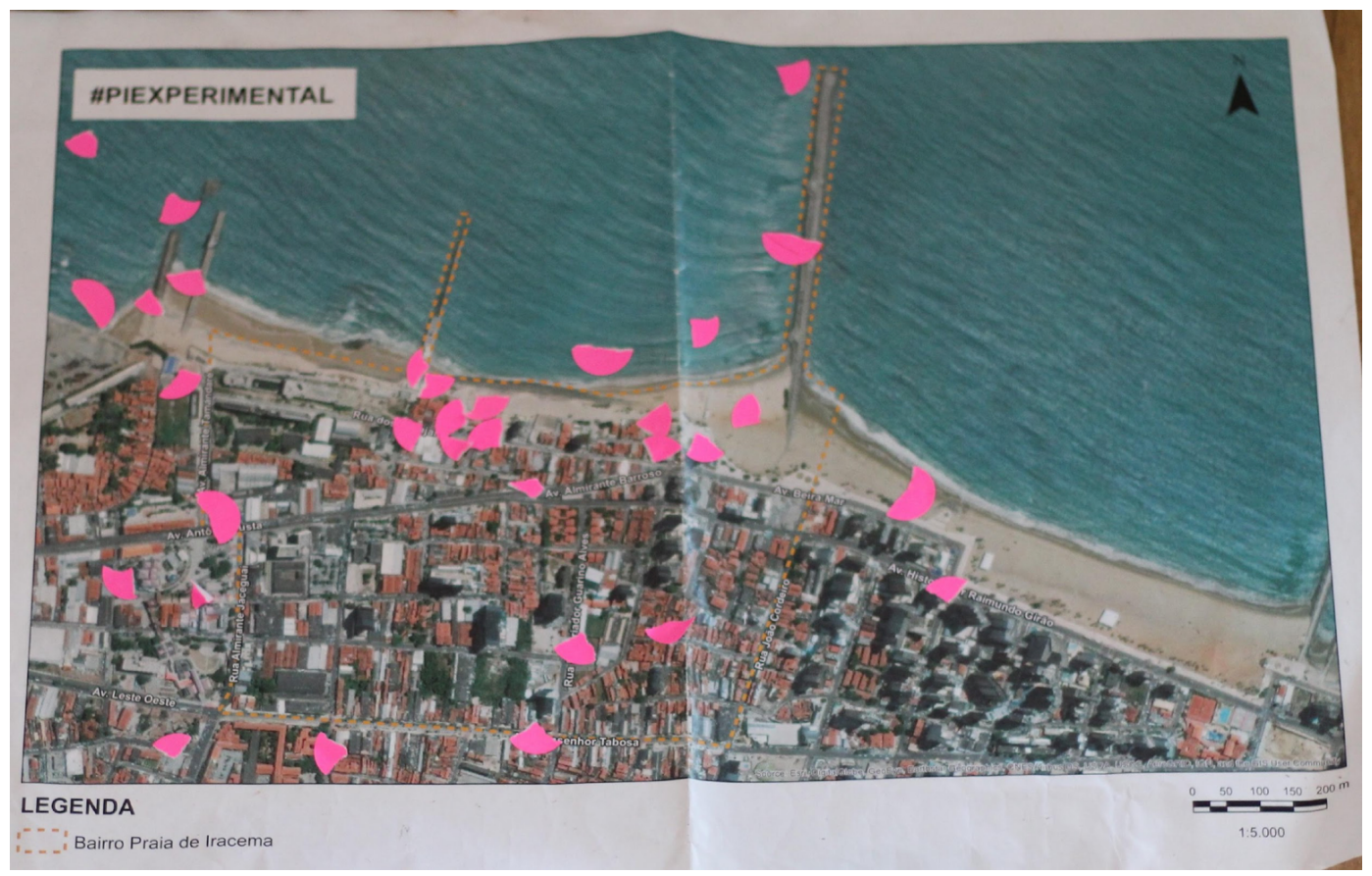

\section{Caminhada}

Em referência à deriva psicogeográfica dos Situacionistas, movimento artístico-político internacional que surgiu ao final da década de 60, foram desenhados encontros para percorrer o bairro a pé na ideia de que "a cidade é um jogo a ser utilizado para o próprio aprazimento, um espaço para ser vivido coletivamente e onde experimentar comportamentos alternativos" (Careri, 2013, p. 98). Foram executadas caminhadas: 1) pelos principais pontos históricosculturais, guiada pelo morador, geógrafo e contador de histórias Joaquim; 2) pelos limites do bairro, de acordo com o IBGE; 2) pelas ruelas e zonas centrais fora do eixo turístico. Permitiuse reordenar o trajeto conforme o grupo desejava, tornando adaptáveis até mesmo os roteiros pré-concebidos.

A caminhabilidade foi utilizada enquanto técnica de apreensão do território, resgatando o corpo-presença na dinâmica urbana (Figura 4). Por ter sido executado durante a pandemia de Covid-19, o caminhar em espaço aberto (respeitando as medidas de segurança) também serviu como prática para integração interna entre pesquisadoras, assim como vínculo entre o grupo e o próprio bairro. Os trajetos foram espaços para surpresas, encontros e descobertas, importantes para a pesquisa no território pelo contato direto com a infraestrutura do bairro, bem como pela aproximação segura entre agentes e desejos de melhoria do urbano. 
Figura 4: Caminhada técnica-sensitiva pelas ruas da Praia de Iracema. Fonte: Arquivos do projeto

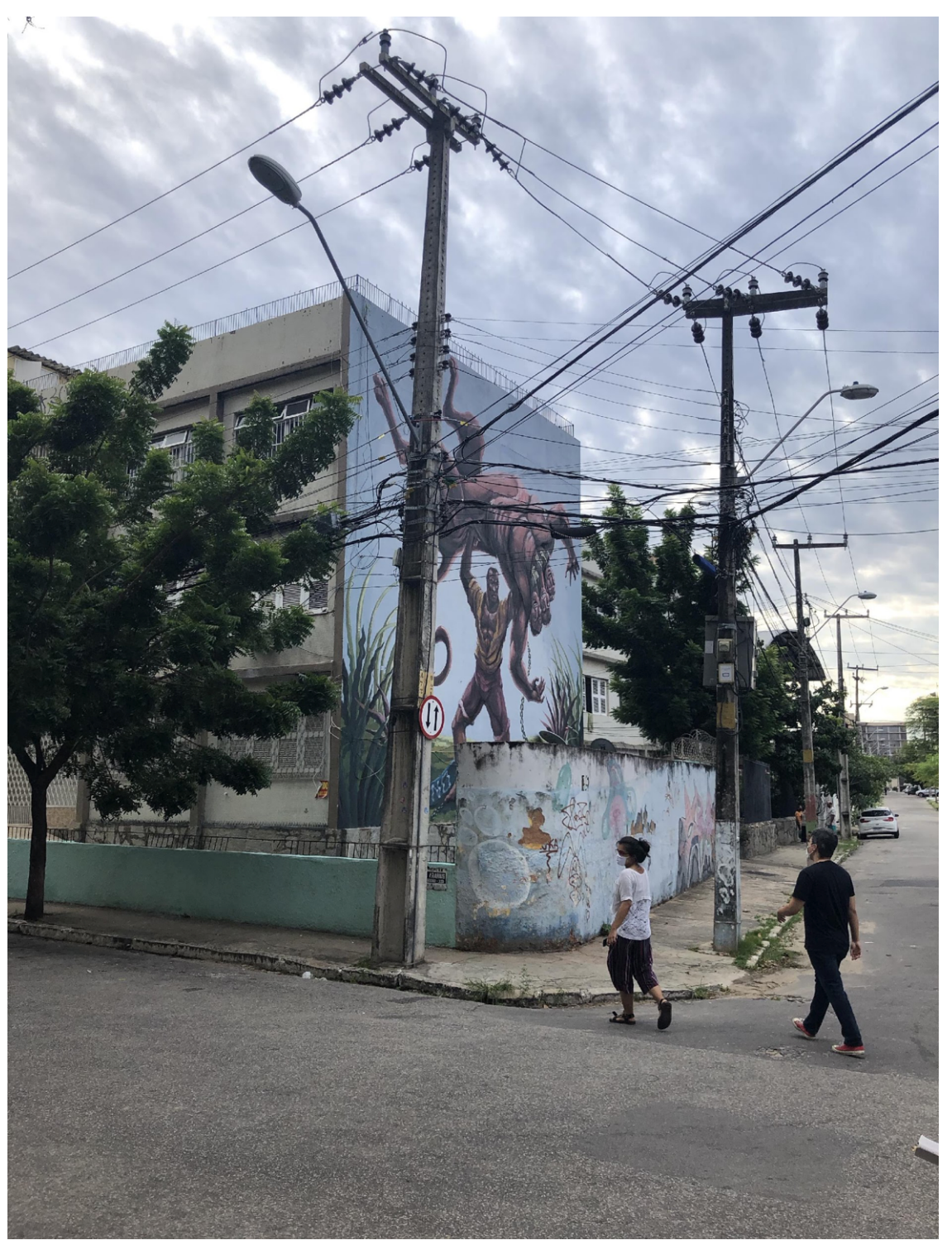

\section{Processo cíclico}

O plano em ciclos se faz importante por ilustrar ideias de tempo e ritmo no projeto. Por se tratar de um trabalho social, o estabelecimento de rotina através de encontros periódicos serve como base para a investigação, trazendo novos olhares a partir da frequência de contato com o objeto em estudo. As reavaliações e melhorias são impulsionadas pelas etapas de "Vistoria", onde a equipe compõe reuniões de aprendizados, ajustes e adaptações das atividades do cronograma. O processo como foi articulado permite a reconstrução da imersão através da etapa "(Re)Ciclo", onde papéis poderiam se inverter, a exemplo de mentorias reversas entre as participantes, alteração na ordem dos encontros ou transformação nos tons da narrativa coletiva. A configuração cíclica da jornada também se dá nas pausas: entre o final de 2020 e o início de 2021 houve um recesso de maior duração, enquanto o trabalho se distribuía duas vezes por semana, cabendo espaços de respiro entre as atividades. 
A rotatividade no projeto permite que seja cultivada uma inteligência do próprio grupo, possibilitando atividades de reengenharia e incorporando elementos que surgem da experiência em si. Trata-se, portanto, de uma técnica para consolidação e revisão de procedimentos padrões. Esse convite para a reconstrução também é observado nas teorias do metadesign que, segundo Vassão (2017), pode ajudar a reorganizar um conjunto de métodos e ferramentas cognitivas que se dedicam à inovação no contexto das cidades, além de criar novos significados e contribuir diretamente para uma nova dinâmica político-urbana.

\section{Instrumentos de coleta e análise de dados}

Foram utilizados serviços gratuitos do Google como base para estruturação dos dados. Os arquivos de pesquisa bibliográfica, referências teóricas, documentos, recortes jornalísticos, assim como atividades internas da equipe foram armazenadas em Drive, de modo que houvesse sincronização no acesso facilitando o trabalho remoto. Dentre os amplos usos de ferramentas, destacam-se: os formulários, para chamada de participantes e coleta de satisfação pós-execução; as planilhas e slides, pra organizar fases da jornada, controles internos e estruturar apresentações; o quadro Jamboard (Figura 5), para dinâmicas de cocriação e montagem assíncrona de inputs; e sala virtual de vídeoconferência.

Figura 5: Print da tela do jamboard na reorganização de post-it dos mapas conceituais para a criação de narrativas. Fonte: Arquivos do projeto

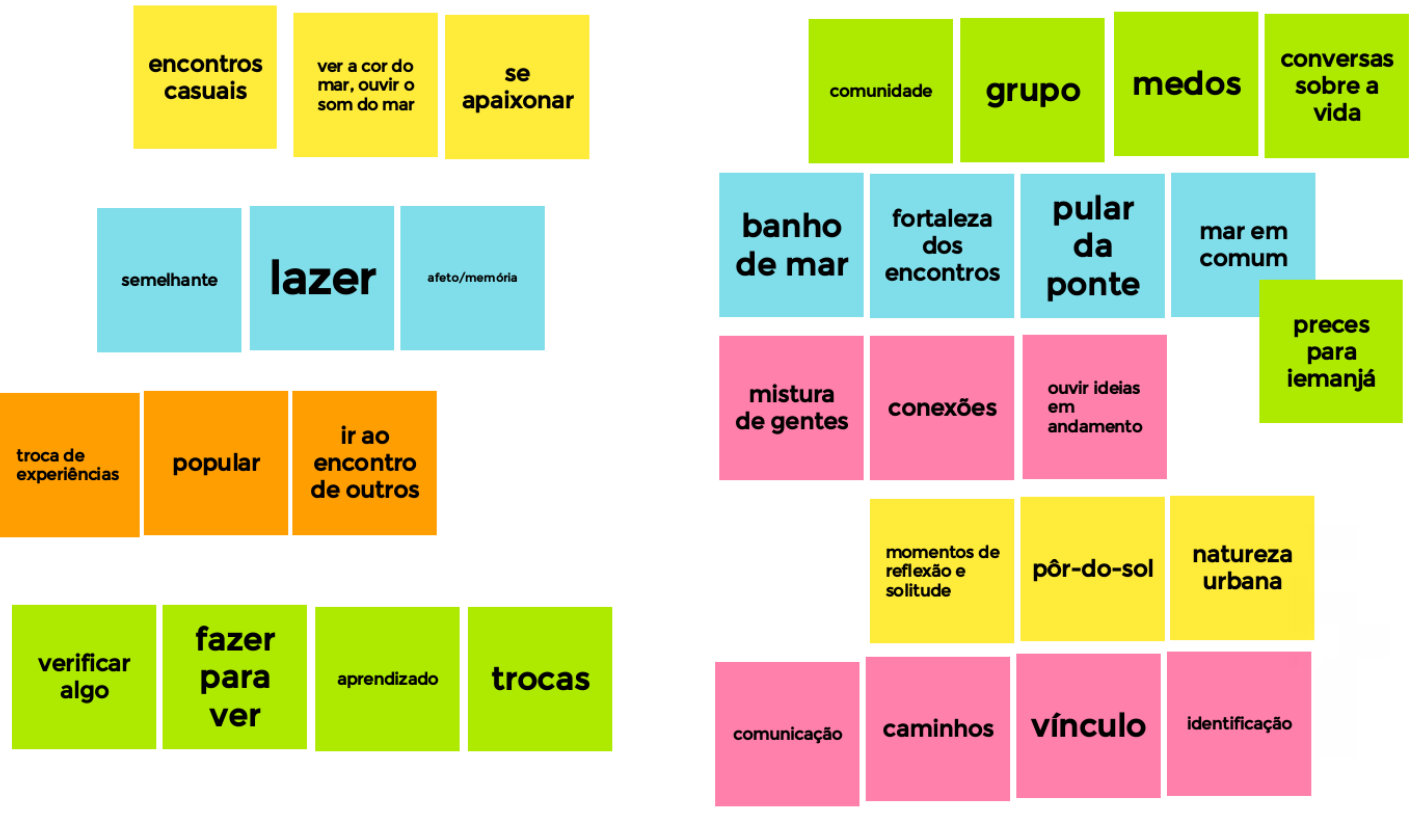

Além dos recursos digitais, a coleta e análise de dados também se deu a partir de experimentos analógicos. Cada integrante selecionada para a equipe investigadora recebeu um "kit para pesquisadoras" contendo artigos de papelaria: um diário de bordo para acompanhamento da jornada, adesivos de cores variadas, marcadores e notas adesivas. Esse material foi utilizado em atividades presenciais para co-criação a partir de ferramentas visuais 
de gestão e design, servindo também como instrumento para simulação e discussão estrutural para arquiteturas de informação, fluxos de trabalho e decomposição analítica de soluções.

Os encontros presenciais, especialmente nas visitas técnicas a campo, contaram com fotografias, captação de vídeos, anotações e mapas impressos para registrar informações sobre o lugar, a fim de captar sensações decorrentes da experiência com o urbano. Tais arquivos aliados às ferramentas híbridas citadas acima serviram de apoio a processos de tomadas de decisão do grupo, resgatando imagens, notas escritas, vivências e depoimentos coletados em entrevistas.

A partir do design do processo, foi destinado tempo excluso para agrupamento de perspectivas e alinhamento de expectativas da equipe. As "OBSERVAÇÕES" faziam parte do ciclo de imersão e serviam como espaço de discussão sobre as impressões e conteúdos emergentes até então, enquanto nos "APRENDIZADOS" buscava-se compreender pontos fortes e fracos do desenvolvimento, discordâncias entre o que foi planejado e aquilo que foi realizado, rearranjar ou modificar passos do projeto. Nesses encontros os dados eram analisados principalmente a partir da comparação de documentos existentes, sendo eles próprios ambientes de processamento e construção da informação.

\section{Procedimentos}

Como modo de introdução ao trabalho com dados, resgatando os mapas conceituais, a equipe foi convidada a brincar com as palavras e definições levantadas até então. Exercícios para hierarquização de dados foram propostos como jogos: servindo-se de artigos de papelaria (adesivos e marcadores), eram distribuídos votos entre os participantes dos encontros (pesquisadoras e possíveis convidados) a fim de que o grupo delimitasse graus de importância entre temáticas abordadas e emergências para futuro plano de ação.

Além de trazer de modo intuitivo a análise de riscos, as experiências de hierarquização serviam para priorizar desejos comuns de pesquisa e auxiliar a tomada de decisão na execução do projeto. Os votos ora eram individuais, sendo contabilizados utilizando como métrica a concentração numérica, e ora eram coletivos, estimulando a discussão das possibilidades e exercendo a convergência comum entre as ideias propostas.

Outro procedimento orientado a dados eram os agrupamentos (Figura 6) das entradas coletadas pela investigação. Com frequência arquivos de imagem e vídeo, anotações, mapas, recortes bibliográficos e jornalísticos eram postos em um mesmo plano neutro (este poderia ser digital ou analógico, a exemplo de um quadro virtual ou o chão de uma sala) para que fossem criados clusters e, portanto, ordenamento da informação. A montagem desses grupos, se e quando acordados coletivamente, prestavam como base para o desenho de narrativas e também para o armazenamento de dados estruturados. 
Figura 6: Agrupamentos imagem-texto. Fonte: Arquivo do projeto.

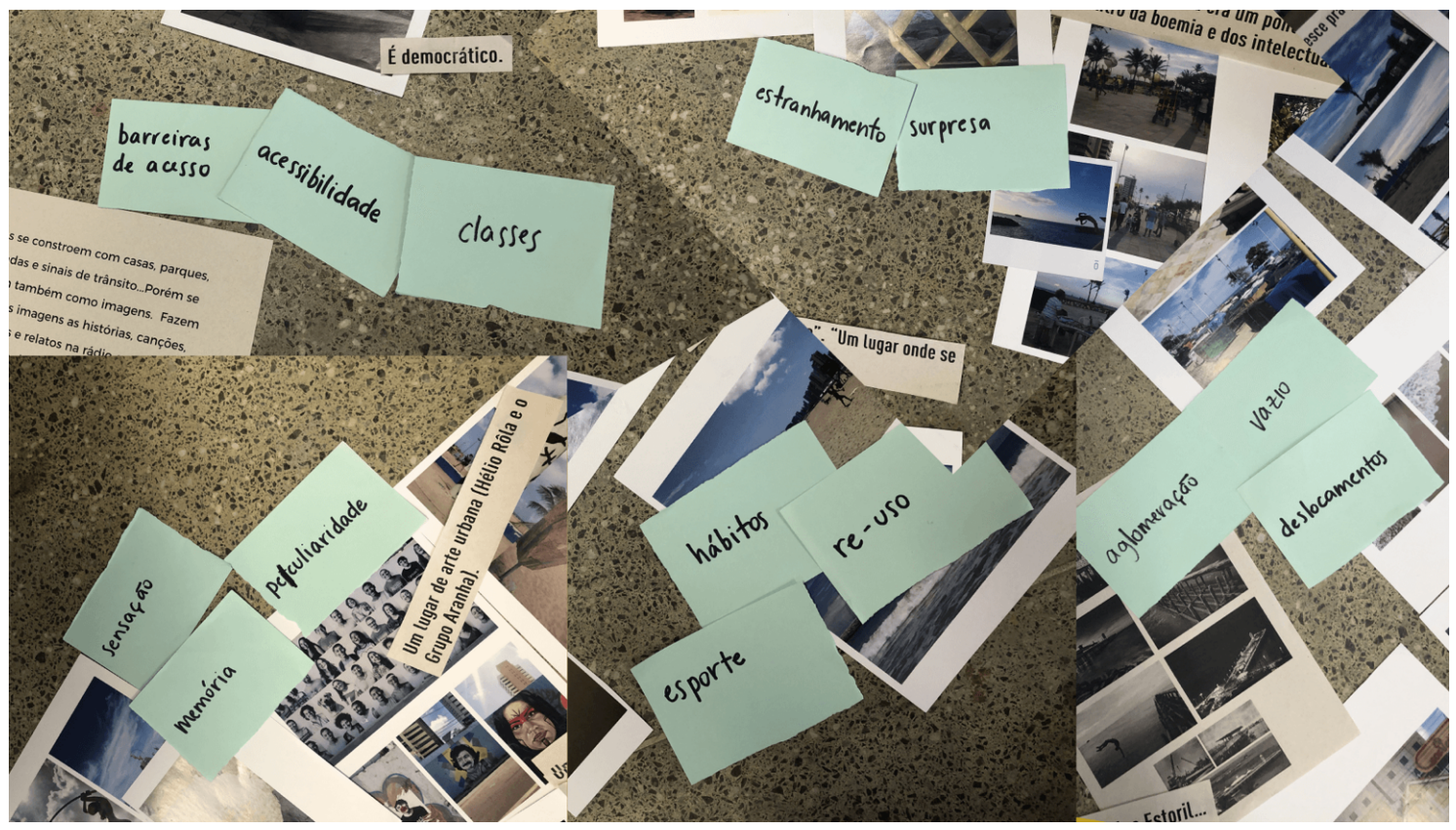

\section{Resultado/Discussão}

Os resultados do PI EXPERIMENTAL estão intimamente ligados ao próprio processo. desenho metodológico foi utilizado para a promoção de um ambiente de aprendizagem híbrido, com abertura ao novo. Embora os laboratórios cidadãos sejam espaços para desenvolver protótipos, foi considerada enquanto entrega do projeto a produção de "objetos comunicadores" sobre o bairro Praia de Iracema. A proposta de adotar um produto final ajudou na materialização da investigação e atuou como conforto para a equipe na ansiedade intrínseca de seguir um programa experimental. A partir do volume de dados coletados durante os ciclos de aprendizagem, foram realizados os seguintes objetos:

1. Lambe-lambes (Figura 7): num total de 27 cartazes espalhados em muros e postes, carregando imagens, frases de impacto e termos "emergências" para o espaço físico do bairro;

2. Mini-documentário: produção audiovisual com dois episódios agrupando depoimentos de mulheres pesquisadoras e empreendedoras que possuem relação ou atividade no bairro;

3. Presença digital: através de perfis nas plataformas Instagram (como meio de comunicação e divulgação de novidades), Youtube (como acervo de produções autorais da pesquisa e curadoria de vídeos referentes ao bairro) e Padlet (como mural educativo, reunindo atividades realizadas no processo de investigação), além de uma página web reunindo informações gerais do projeto e encaminhando para a pasta aberta no Drive (como biblioteca compartilhada do projeto). 
Figura 7: Lambe-lambe aplicado na rua. Fonte: Arquivo do projeto, 2020.

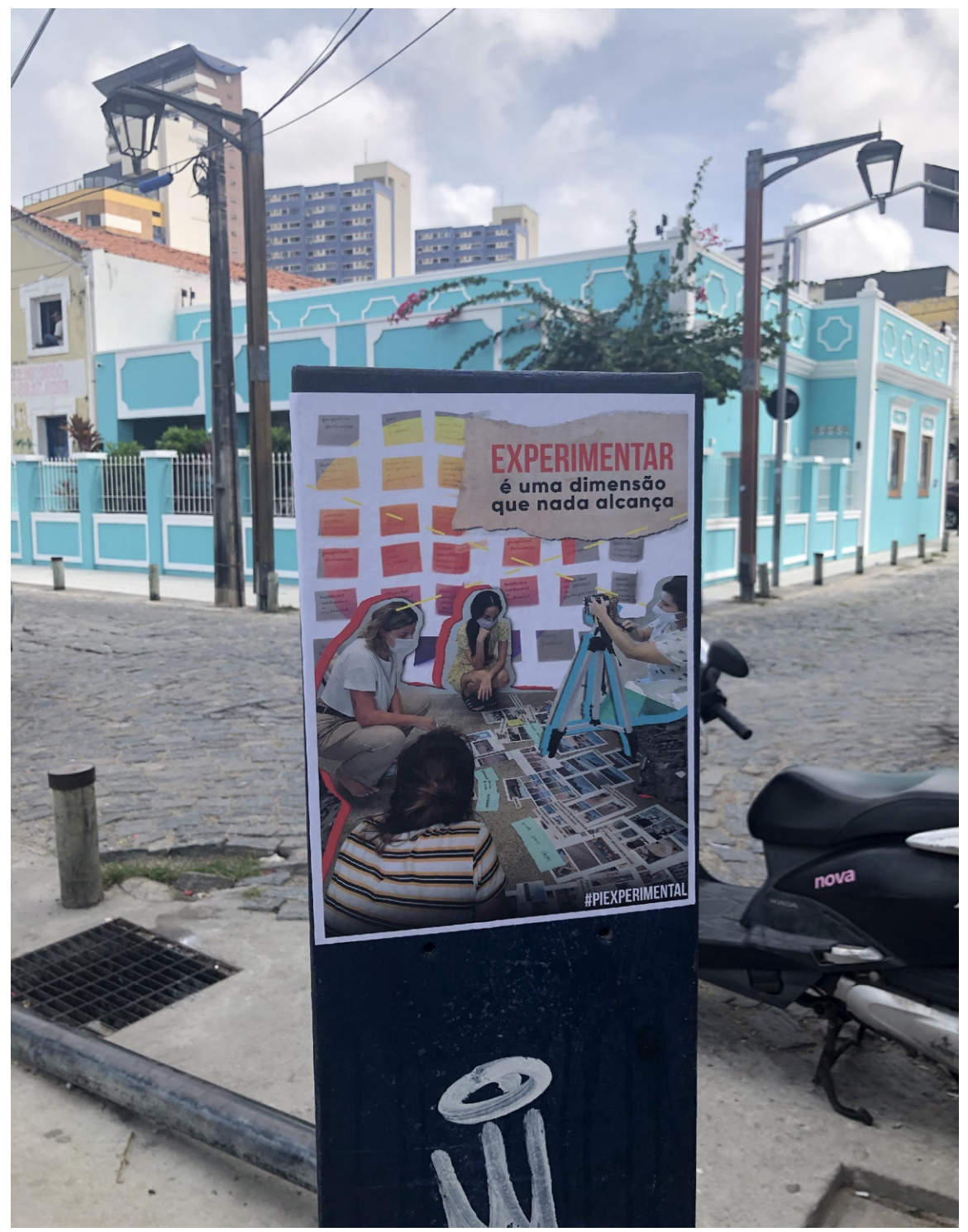

Através de um formulário distribuído no grupo de comunicação do PI EXPERIMENTAL via WhatsApp, foram coletadas impressões sobre as contribuições do projeto nos seus principais integrantes (Figura 8). Por ter percorrido histórias, memórias e desejos de mudança, percebese o laboratório como um espaço comum seguro para viver a cidade e a Praia de Iracema, apesar do distanciamento social. Os quatro meses de pesquisa evocaram debates da ciência aberta, comunicação acessível, humanização dos objetivos urbanos e direito à cidade.

Como continuidade da formação inicial, o grupo foi selecionado para compor, junto a outras nove iniciativas brasileiras, o Laboratório de ações práticas para a mobilidade a pé (LAB.MaP) do Projeto COMO ANDA (SP). Por utilizar da caminhada enquanto ferramenta de entendimento do território e prática estética-política, a equipe se propôs a co-criar um novo produto comunicacional voltado especificamente à mobilidade ativa de mulheres no território da Praia de Iracema. O LAB.MaP tem duração de cinco meses e está sendo desenvolvido no momento de escrita deste documento com objetivo de conscientizar e sensibilizar a sociedade acerca das vulnerabilidades da caminhada feminina nas ruas do bairro. 
Figura 8: Respostas do formulário de satisfação pós-projeto. Fonte: Arquivo do projeto, 2020.

O que mais te instigou no processo do PI EXPERIMENTAL?

7 respostas

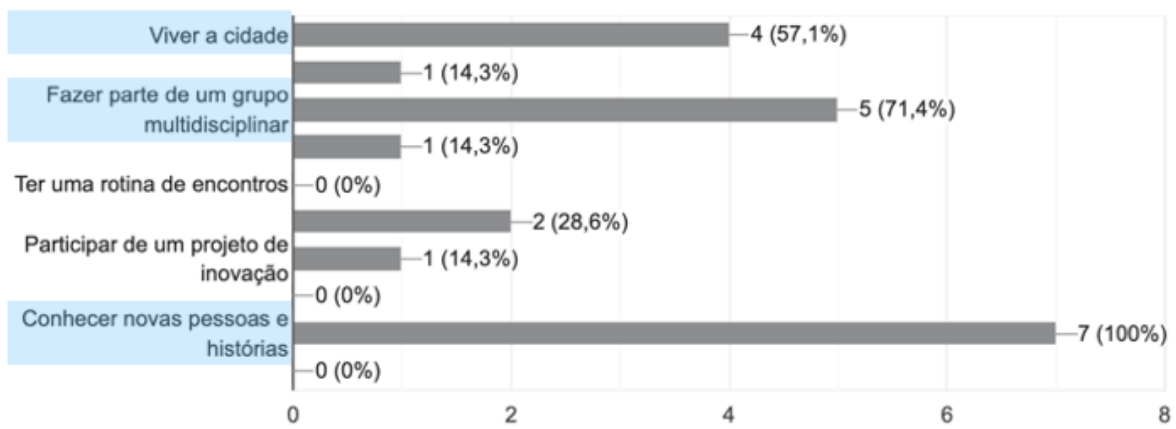

Em quais temáticas você se aprofundou com o desenvolvimento do projeto?

7 respostas

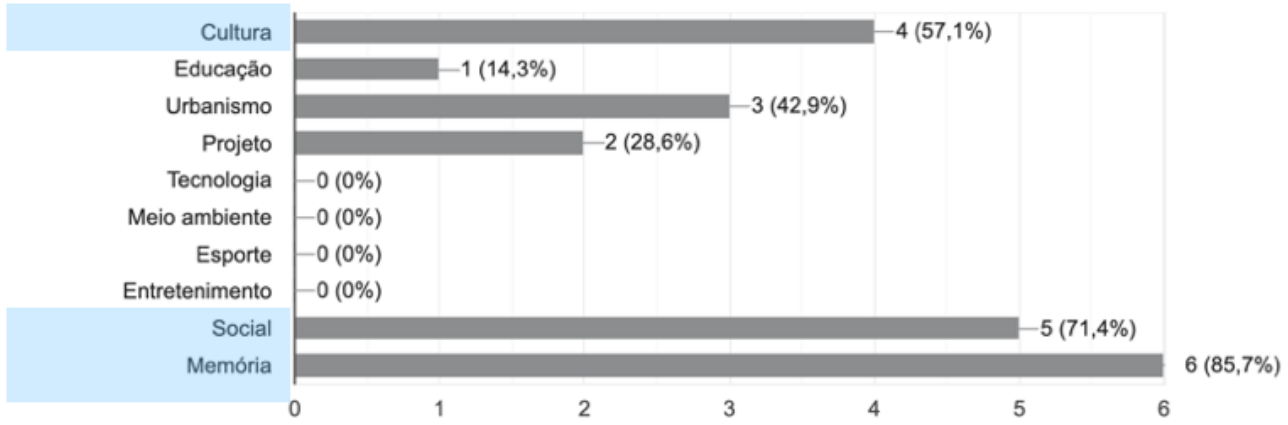

\section{Conclusão/Considerações finais}

O projeto PI EXPERIMENTAL concluiu as tarefas referentes ao edital CRIA PI e manteve a composição da equipe investigadora. Ainda que sem o inicial financiamento, as mulheres pesquisadoras decidiram se manter unidas e dar continuidade às pesquisas envolvendo o território. Apesar do caráter de auxílio das bolsas fornecidas na fase descrita neste documento, é constantemente debatida entre o grupo a necessidade e urgência da valorização, inclusive econômica, das atividades de produção de conhecimento. Reconhecendo a importância de desenvolvimentos urbanísticos que partem da sociedade civil e de programas experimentais para a educação cidadã, o projeto pode ser encarado como protótipo para aproximação da população na inovação social: um modelo a ser aprimorado e reconstruído em outros territórios, a partir de grupos diversos, a fim de estimular a ciência comum.

Por ter se desenvolvido em contexto pandêmico, a jornada foi um teste de intervenção na cidade a partir de práticas híbridas. Em meio às dúvidas sobre como e até que ponto seria possível interagir nos espaços públicos, o grupo explorou possibilidades físicas e 
transformações digitais a partir da co-criação de um espaço de ensino-aprendizagem circundado pelas dinâmicas do projeto. Ainda que embrionária, a iniciativa buscou adentrar os desafios da abordagem comunitária e da comunicação acessível entre lugar-pessoas. A partir da experiência, provoca-se a micropolítica do fazer autogerido e a inteligência em cidades a partir da potencialização das capacidades humanas. Põe-se em pauta a reversão da lógica produtiva urbana voltada a resultados imediatos por um pensamento que investe em processos para desenhos ecossistêmicos do futuro.

Aderindo ao pensamento "Pensar local, agir global", o desenho do projeto contempla importantes discussões contemporâneas. Percebe-se conexão direta entre os Objetivos de Desenvolvimento Sustentável propostos pela Organização das Nações Unidas (ONU), em especial às agendas de Igualdade de Gênero (ODS 5) e de Cidades e Comunidades Sustentáveis (ODS 11). Foram utilizadas desde referências fortalezenses a estrangeiras, sempre levantando debate de como adaptar tendências, termos e práticas de inovação urbana aos contextos focais e latino-americanos.

\section{Referências}

Bensusan, N. (2019). Do que é feito o encontro. - Brasília : IEB Mil Folhas.

Bezerra, R.G. (2008). O bairro Praia de Iracema entre o "adeus" e a "boemia": usos, apropriações e representações de um espaço urbano. Disponível em:

<http://repositorio.ufc.br/bitstream/riufc/6247/1/2008-TESE-RGBEZERRA.pdf>. Acesso em: 12/maio/2021.

Bondía, J. L. (2002). Notas sobre a experiência e o saber da experiência; tradução de João Wanderley Geraldi.

Careri, F. (2013) Walkscapes: o caminhar como prática estética ; prefácio de Paola Berenstein Jacques: [tradução Frederico Bonaldo]. — 1. ed. — São Paulo : Editora G. Gili.

Frascara, J. (2000). Diseño gráfico y Comunicación. — Buenos Aires, Ediciones Infinito, 2000.

Freire, P. (2004). Pedagogia da autonomia: saberes necessários a prática educativa. São Paulo: Paz e Terra.

Gehl, J. (2015). Cidades para pessoas; tradução Anita Di Marco. 3. ed. São Paulo: Perspectiva.

Guatelli, I. (2012). Arquitetura dos entre-lugares: sobre a importância do trabalho conceitual. São Paulo: Editora Senac São Paulo.

Han, B. (2019). Sociedade da transparência; tradução de Enio Paulo Giachini. Petrópolis, RJ: Vozes.

Kalbach, K. (2017). Mapeamento de experiências: um guia para criar valor por meio de jornadas, blueprints e diagramas / traduzido por Eveline Vieira Machado. Rio de Janeiro: Alta Book.

Knemeyer, N. (2003). Information Design: The Understanding Discipline. Disponível em: $<$ http://online.sfsu.edu/jkv4edu/2DMG/projects/infodesign_boxarrows.pdf >. Acesso em: 12/maio/2021. 
Lafuente, A. (2015). Repertorios conceptuales, itinerarios contrastados y prácticas colaborativas de los laboratorios innovación social. Escuela de Educación, Humanidades y Ciencias Sociales TEC Monterrey, Campus Ciudad de México, Tlalpan, DF.

Massironi, M. (1937). Ver pelo desenho. Portugal: Edições 70.

Risler, J. \& Ares, P. (2013). Manual de mapeo colectivo : recursos cartográficos críticos procesos territoriales de creación colaborativa / Julia Risler y Pablo Ares. 1a ed. Buenos Aires: Tinta Limón.

Rogers, R. (2011). Cities for a small planet. Faber and Faber Limited, Londres.

Vassão, C. (2017). Design and Politics: Metadesign for social change. Strategic Design Research Journal.

Wurman, R. S. (1991). Ansiedade de informação. São Paulo: Cultura Editores Associados.

\section{Sobre a autora}

Ariane de Almeida Mendes, bacharel em engenharia de produção mecânica e mestranda em artes, UFC, Brasil, <deamariane@gmail.com> 